\title{
TEKSTUR LAKON DRAMA BANGSAWAN RAJA KECIL PRODUKSI SANGGAR TEATER MATAN PEKANBARU
}

\author{
M. Nazri \\ Pascasarjana Institut Seni Indonesia Padang Panjang \\ muhammadnazri.ayi19@gmail.com
}

\begin{abstract}
Bangsawan drama is a traditional Malay theater in Riau. The play presents about life around the kingdom, presented according to the custom and the rules that have been determined. The original Malay stories that made into Bangsawan drama performances are Hang Tuah Lima Bersaudara, Sultan Mahmud Mangkat Dijulang and Laksamana Bintan. The story of Raja Kecil was taken from the history of the founder of Siak Kingdom which is packed into very interesting form of theater to be studied. The object of this study focuses on the texture of the play in the performance of the Raja Kecil. This research uses Dramaturgy theory by using a descriptive qualitative approach method. The process of interviewing, observing, documenting are the ways that have been through to find out the play texture.
\end{abstract}

Keywords: Bangsawan Drama, Play Texture, Matan Theater

\section{Pendahuluan}

Teater

merupakan

pertunjukan kesenian yang

dipentaskan di panggung

melibatkan pemain sesuai

kebutuhan pertunjukan.

Memainkan kisah lakon baik

berangkat dari peristiwa sejarah,

lagenda, hikayat, menggabungkan

unsur tari, musik, dan lakon.
Teater sering disebut juga dengan istilah drama.

Japi Tambajong (1981:

61) menjelaskan teater di Indonesia terbagi menjadi dua bentuk, yaitu teater tradisonal dan teater modern. Drama bangsawan tergolong dalam teater tradisional lainnya di kepulauan Indonesia. Pada mulanya tontonan ini 
dilangsungkan di keraton, untuk menghibur sang raja dan para bangsawan.

Drama bangsawan merupakan salah satu bentuk teater tradisi melayu yang mengetengahkan lakon tentang kehidupan di sekitar kerajaan yang disajikan menurut aturan kebiasan yang telah ditentukan. (Ahmad Dharmawi, 2004:63). Drama bangsawan ini pada masa lampau bernama "Wayang Parsi". Sumber sejarah India menjelaskan bahwa ketika Islam masuk ke Persia (Iran Sekarang) orangorang majusi yang tak mau masuk agama Islam banyak melarikan diri ke India. Kota di India yang paling banyak berpenduduk berasal dari keturunan mereka ialah Bombay. Jadi yang datang ke Pulau Pinang pada tahun 1870an bukanlah kumpulan wayang dari Iran tetapi salah satu kota dari India (Amanriza, 1993: 97).

Drama bangsawan di dalamnya terdapat silat, tarian, dan nyanyian yang menjadi sebuah alur untuk memperkuat pertunjukan. Hal ini agar pertunjukan menjadi lebih menarik dan tidak membosankan. Tari dan nyanyian disajikan dalam pergantian adegan dan pergantian setting, karena pergantian setting dalam pertunjukan bangsawan memakan waktu, disebabkan pertunjukan bangsawan menampilkan setting balairung istana, gerbang kerajaan, juga setting di dalam rumah. Drama ini juga dipenuhi berbagai properti, seperti singasana raja, kursi raja, dan tempat duduk para pembesar kerajaan.

Pertunjukan drama bangsawan Raja Kecil oleh sanggar teater Matan dipentaskan di Gedung Anjung Seni Idrus Tintin Pekanbaru Riau. Pementasan berlangsung malam hari tanggal 1 dan 2 Desember 2017, dengan durasi satu jam dua puluh empat menit. Naskah yang ditulis Hang Kafrawi tersebut berangkat dari sejarah Kerajaan Siak Sri Indrapura. Pertunjukan 


\begin{tabular}{|c|c|}
\hline $\begin{array}{l}\text { tersebut disutradarai Rhiky } \\
\text { Pranata dengan jumlah } \\
\text { pendukung } 27 \text { orang terdiri dari } \\
\text { aktor, penari, dan pemusik. }\end{array}$ & $\begin{array}{l}\text { keluar ruangan hingga } \\
\text { pertunjukan selesai. Mereka } \\
\text { bertahan dan menikmati. Oleh } \\
\text { karena itu, penulis merasa tertarik }\end{array}$ \\
\hline Naskah & pertunjukan \\
\hline $\begin{array}{l}\text { merupakan drama bangsawan } \\
\text { yang berangkat dari sejarah yang }\end{array}$ & $\begin{array}{l}\text { Drama Bangsawan Raja Kecil } \\
\text { dengan memfokuskan kajian pada }\end{array}$ \\
\hline mengisahkan tokoh sentral pendiri & tekstur \\
\hline Kerajaan Siak di Provinsi Riau. & menggunakan teori Dramaturgi. \\
\hline $\begin{array}{l}\text { Tahun } 1722 \text { tahta Johor direbut } \\
\text { oleh iparnya Tengku Sulaiman. }\end{array}$ & $\begin{array}{l}\text { Tekstur lakon yang penulis teliti } \\
\text { hanya berpokus pada dialog, }\end{array}$ \\
\hline Raja Kecil mengundurkan dirinya & moud/rithem/suasana \\
\hline Bintan, kemudian & spektakel. \\
\hline Bengkalis, dan selanjutnya & kan adalah metode analisis \\
\hline nendirikan pusat kerajaan & \\
\hline
\end{tabular}

Buantan. Itulah awal berdirinya

kerajaan Siak Sri Indrapura

(Effendy, 1987: 2).

\section{Pembahasan}

\section{Tekstur Lakon}

Pertunjukan drama

bangsawan Raja Kecil ini

menghadirkan peristiwa sejarah di atas pangung. Penulis yang turut menonton pertunjukan merasa terpukau. Menurut pengamatan penulis, para penonton lain juga turut menikmati pertunjukan yang ditandai dengan ekspresi wajah yang serius saat mereka menonton dan tidak ada penonton yang

Tekstur Lakon adalah unsur-unsur yang terdapat dalam lakon yang menjadi pijakan dalam penyusunan desain pertunjukan. Jika penyabaran dan analisis struktur lakon merupakan unsur yang bertujuan unyuk menciptakan pemahaman makna, maka tekstur lakon merupakan bagian dari proyeksi lakon yang sudah dapat dirasakan dan diraba. 
Bagian yang dibahas dalam karakteristik tokoh seperti dibahas tekstur lakon adalah: dialog, di atas; dan tentu saja ia moud/suasana dan spektakel. merupakan perwujudan tema dari Penjabaran tekstur lakon Raja sebuah cerita; atau melaluinyalah Kecil sebagai berikut:

\section{Dialog}

Dialog adalah percakapan yang terjadi antara tokoh satu dan tokoh lain dalam sebuah pertunjukan/lakon. Dialog selain berfungsi memberikan informasi tentang karakter tokoh juga berperan menciptakan alur cerita, menegaskan tema, latar cerita juga menentukan tempo atau irama pemainan. Pertunjukan naskah drama bangsawan Raja Kecil karya Hang Kafrawi yang disutradarai Rhiky Pranata, produksi Sanggar Teater Matan menggunakan bahasa Indonesia campur bahasa Melayu.

Menurut Soemanto (2001:

22) dialog merupakan wujudan pikiran dan perasaan dari para tokoh. Ini artinya, ia sejajar dengan aksi/tindakan dalam masalah pengungkapan sebuah cerita itu diwujudkan, persisnya merupakan dalam bentuk peristiwa-peristiwa, yang terjadi melalui dialog, yang menjalin secara sebab-akibat dan membentuk sebuah alur.

Sementara Yudiarni (2002: 362) mengatakan, bahwa sebuah dialog harus dapat memberikan keterangan tentang kejelasan cerita; ia harus bisa mendukung jalannya suatu alur. Tetapi ia juga harus mampu membentuk suasana-suasana yang benar-benar dapat (membawa) dirasakan oleh penonton yang mendengarkannya; sebuah dialog harus dapat memberikan kesempatan bagi penonton untuk mengalami dan merasakan suatu pikiran dan sikap hati yang ada/tersimpul di dalam dialog tersebut.

Ada sebuah kekhasan tentang komponen ini berkaitan 
dengan teater Bangsawan, yakni: kehalusan dalam bertutur. Sebagai teater yang berjiwakan ajaran Islam, teater Bangsawan ini sangat mementingkan segi keadaban dalam berucap, seperti dicontohkan Nabi agama Islam yang selalu berbicara secara halus dalam kondisi apa pun. Tapi ini bukan ketundukan yang buta; kesediaan dalam penerapannya juga berlandaskan pada kesadaran bahwa perkataan yang dikemukakan secara halus dan santun akan lebih cepat dan lebih mudah diterima oleh siapa saja dibanding apabila dilakukan secara datar, apalagi kasar. Karena teater ini juga merupakan sarana untuk menyebarkan nilainilai budaya Melayu, maka kehalusan itu pun harus dipadukan ke dalam pengucapanpengucapan yang khas gaya Melayu, berupa bidal, umpama, peribahasa, atau petatah-petitih.

Kehalusan adab bertutur itu, penulis amati, masih tetap dijaga oleh teater Matan, khususnya dalam cerita raja Kecil karyanya Hang Kafrawi ini. Bahkan tokoh Tengku Sulaiman yang dendam-kesumat, ketika membantah ucapan raja Kecil saat pertemuan menjodohkan adik sulungnya dengan raja tersebut, ditampilkan sebagai seorang yang tetap menggunakan ucapanucapan kiasan yang cukup santun.

"Tuanku, kedatangan
Tuanku seperti cahaya
purnama membahana ke
pelosok jiwa hamba"
(Riayat Syah)
"Pujian selalu membuat
manusia kehilangan jiwa
dan akhirnya bisa
membinasakan segala raga
yang kita punya. Datuk
Bendahara, janganlah
terlalu memuji beta, nanti
beta kehilangan rupa",
(Raja Kecil)

"Seorang raja memang sepantasnyalah dipuja oleh hamba sahayanya, (Tengku Sulaiman)

"Tidak begitu Tengku. Seorang raja yang bijaksana dipuja bukan karena tahtanya, tetapi segala kerjanyalah yang pantas dipuja, itu pun 


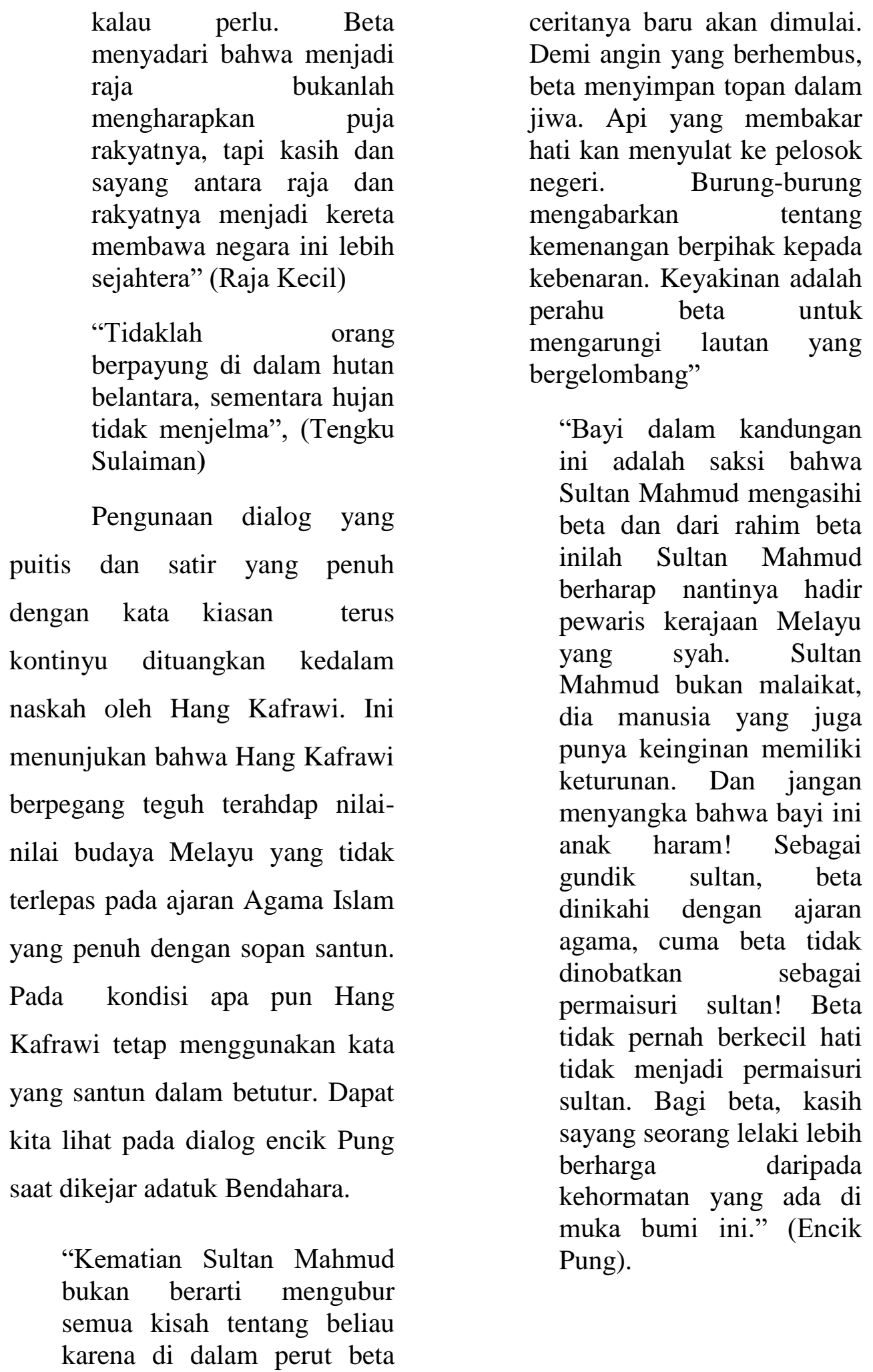




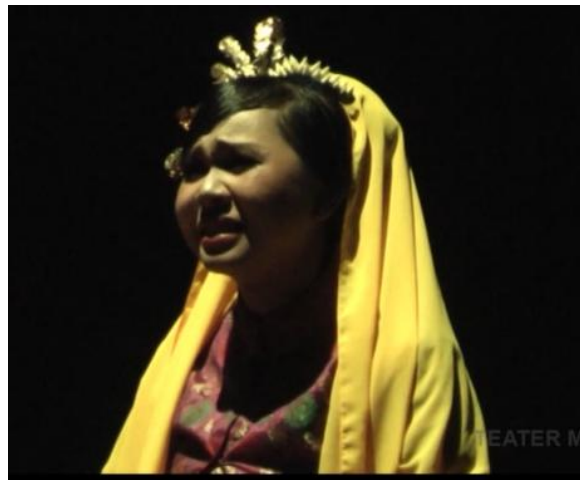

Gambar 1. Adegan saat dialog Encik Pung dikejar Datuk Bendahara Pada Pertunjukan Teater Matan di Anjung Seni Idrus Tintin, 2 Desember 2017

\section{Moud/Rithem/Suasana}

Mut atau sering juga disebut dengan istilah The methor adalah sebuah cara bermain yang sedemikian rupa disusun guna memperbaiki teknik akting serta membawakan peran yang lebih sempurna (Arymawan, 1993:180).

$$
\text { Yudiaryani dalam }
$$

\section{Panggung Teater Dunia} mengatakan bahwa irama kalimat, bunyi kata, dan gambaran tokoh yang kaya imajinasi membantu aktor untuk menghadirkan suasana atau mood. Seorang sutradara harus dapat mendiskusikan gerakan-gerakan ritmis kepada aktor untuk memasuki nuansa kelembutan musik (2002: 367).

Dalam naskah Raja Kecil ini sutradara memberi masukan atau menyusun keterlibatan pada irama kalimat dari tokoh satu ke tokoh lain untuk menghadirkan suasana yang tepat sesuai dengan alur dioalog yang dikehendaki naskah. Selain itu musik juga dihadirkan pada pertunjukan untuk memberi implus agar aktor mampu memasuki suasana yang telah diciptakan bersama (Wawancara Pranata, 14 Juli 2018).

Moud, rithem dan suasana sangat penting dalam sebuah garapan pertunjukan teater. Moud, rithem, dan suasana berfungsi sebagai pembangun suasana dalam pementasan. Moud dan rithem yang mampu dimainkan setiap aktor dengan konsisten akan mampu membawa penonton mengalami peristiwa dalam pertunjukan dan masuk kedalam peristiwa tersebut. Itu dibuktikan 
melalui setiap pengadeganan dalam pertunjukkan teater Raja Kecil dari bunyi-bunyian yang menghantarkan seorang aktor untuk memulai kisah sehingga terciptalah suasana yang diharapkan agar penonton semakin terbawa kedalam peristiwa itu.

Adegan terakhir dalam pertunjukkan teater Raja Kecil adalah perkelahian antara Raja Kecil dan Daeng-Daeng. Sutradara menghadirkan video art berlatarkan pantai serta hamparan laut luas serta lighting berwarna merah. Musik yang dihadirkan yaitu musik tengkah gendang silat yang semakin lama semakin semarak. Hal ini untuk menimbulkan efek mencekam bagi penonton sehingga penonton bisa turut terbawa dalam susasana perkelahian tersebut. Dari segi dialog, terdengar suara dari kejauhan saling jual-beli ungkapan dan kekuatan. Kemudian Raja kecil muncul dengan diserang oleh DaengDaeng. Moud semakin terbentuk sejalan dengan rithem dan suasana. Dapat kita lihat pada gambar adegan di bawah ini.

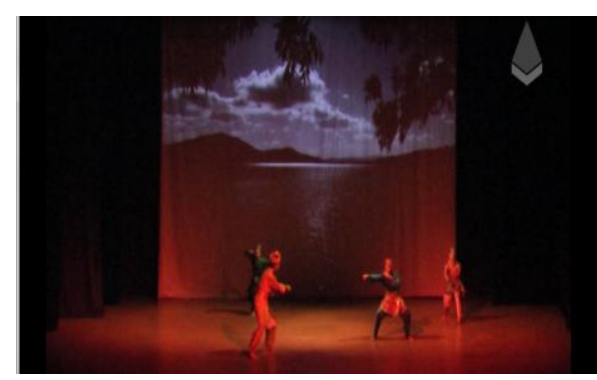

Gambar 2. Adegan Perkelahian Raja Kecil dengan Daeng-Daeng pada Pertunjukan Teater Matan di Anjung Seni Idrus Tintin, 2 Desember 2017.

\section{Spetakel}

Spektakel merupakan aspek-aspek visual yang kedudukannya memperkuat kemunculan komponenkomponen sebelumnya. Sebuah peristiwa akan tampil membingungkan tanpa didukung latar tempat dan tata cahaya yang cocok. Misal, akan terlihat aneh jika seorang karakter pahlawan misalnya, tampil hanya dengan mengenakan busana kaos oblong yang biasa saja. 
Spektakel digunakan aktor untuk menyampaikan pikiran, perasaan, dan watak tokoh. Selain itu, spektakel bagi sutradara digunakan untuk menyusun tindakan secara fisik dan akting bisnis tokoh, keluar masuk aktor, pengelompokkan aktor, memilih kostum dan rias, memilih ruang panggung sesuai dengan penafsiraan naskah. Spektakel meliputi unsur setting, cahaya, properti, busana, rias, dan musik (Yudiaryani, 2002: 364).

\section{Dalam pertunjukan Raja} Kecil, berbagai spektakel dihadirkan. Kemunculan setting kerajaan yang begitu megah ditambah lagi berbagai aktor yang hadir dalam ruang kerajaan serta penari masuk dengan tarian pembukaan. Salah satu adegan tokoh dalam Raja Kecil adalah membuka keris yang melambangkan akan ada sesuatu pertikaian besar. Lighting berwarna merah dipakai saat adegan penikaman serta perseteruan antar tokoh. Semua spektakel itu telah memberikan warna bagi pertunjukan teater Raja Kecil serta memberi rasa bagi penonton yang menyaksikan.

Pada adegan Megat Sri Rama menikam Sultan Mahmud, secara serentak lighting merah menyala, kain putih berkibar bagaikan gelombang, musik bertalu-talu sangat riuh. Tariantarian dimunculkan untuk mensingkronkan tiap-tiap adegan. Hal ini sangat memberikan spektakel bagi penonton, sehingga tarian itu sendiri menjadi berarti dan tidak menjadi kolase saja.

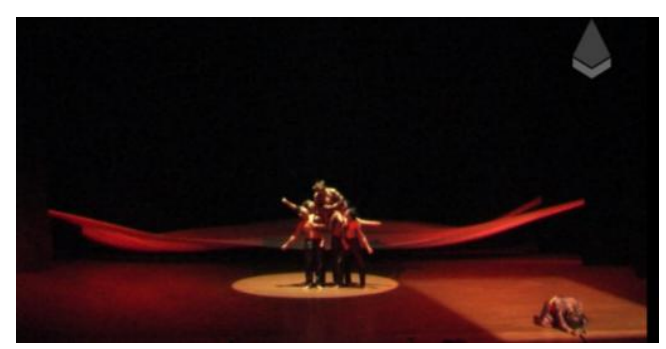

Gambar 6. Adegan Megat Seri Rame Menikam Sultan Mahmud Pada Pertunjukan Teater Matan di Anjung Seni Idrus Tintin, 2 Desember 2017

Dengan tawaran-tawaran spektakel baru yang disuguhkan sutradara, pertunjukan teater Raja 
Kecil ini menjadi semakin pengarang kemudian menarik untuk disaksikan. mengemukakan pandangannya, Penonton tetap berada di tempat karena menganggapnya sebagai duduknya dan tidak berajak sesuatu yang penting untuk sebelum pertunjukan berakhir. ditanggapi; dan ketika

\section{Simpulan}

Dramaturgi adalah teori atau kaidah untuk mencipta karya drama yang indah. Ia memberi pedoman bagaimana mengolah komponen-komponen yang tersusun yang menopang merumuskan pandangannya inilah seorang pengarang itu harus mengacu pada pedoman yang diberikan oleh dramaturgi, sehingga karya cerita yang dirumuskannya diharapkan dapat hadir secara menarik dan menyenangkan untuk disaksikan.

kehadiran sebuah cerita yang akan dipentaskan; komponen ini bisa disetarakan dengan struktur intrinsik karya sastra, bedanya hanya pada segi pengungkapannya yang menjadi dipentaskan, bukannya dituturkan; dan dalam karya pementasan, ia lazim disebut sebagai struktur lakon dan tekstur lakon (pelakonan, atau pertunjukan).

Karya drama itu sendiri merupakan wujud dari gagasannya pengarang; terhadap masalah tertentu, seorang

Cerita Raja Kecil adalah cerita yang berdasarkan sejarah. Ia menceritakan tentang riwayat raja kerajaan Siak yang pertama. Tapi dalam pementasannya, Hang Kafrawi membuat beberapa perubahan segi darinya: mengisahkan bahwa raja ini mempunyai Ayah dari perkawinan yang sah secara agama, memaafkan Bendahara kerajaan yang pengkhianat, dan memenangkan peperangan ketika melawan para pendekar Bugis. Karena karya drama adalah karya 
seni, maka perubahan-perubahan seperti itu adalah niscaya, tak terelakkan; cerita asli yang menerangkan bahwa raja Kecil sebagai seorang raja yang tidak jelas asal keturunannya adalah sebuah masalah, dan Hang Kafrawi boleh-boleh saja mengubah model ceritanya sesuai dengan pandangannya (dan wawasannya, atau ideologinya).

Setelah diperiksa, perubahan itu ternyata dilakukan berlandaskan keinginan memasukkan unsur agama Islam sehingga ceritanya bisa lebih senonoh, dan terkesan ingin mengembalikan wibawa dari raja kerajaan Siak itu yang adalah seorang dari bangsa Melayu, dan perubahan itu ternyata juga bersesuaian dengan rumusan dramaturgi. Karena cerita ini ditampilkan melalui teaternya yang berkarakter Bangsawan (teater Matan), maka khusus untuk komponen dialog, Hang Kafrawi masih mempertahankan pakem adab dan kehalusan dalam bertutur, sedangkan untuk komponen layar latar, dirinya lebih mengutamakan tujuan pokok dari komponen ini, dan kepraktisannya.

\section{Daftar Pustaka}

Amanriza, Ediruslan dan Junus, Hasan. 1993. Seni Pertunjukan Tradisional (Teater Rakyat) Daerah Riau. Pekanbaru: PIDKD Riau

Amsal, Temul dan Ubaidillah, Tengku. Tanpa tahun. Drama Klasik Teater Bangsawan, Seni Pertunjukan dari Riau. Pekanbaru

Bertens, K. 2007. Etika. Gramedia Pustaka Utama: Jakarta

Dahlan, Ahmad. 2014. Sejarah Melayu. Jakarta: KPG

Darmawi, Achmad. 2005. Teater Bangsawan Melayu Riau. Pekanbaru: LSBM-STR

Effendy, Tenas dkk. 1987. Silsilah Keturunan RajaRaja Kerajaan Siak Sri Indrapura dan Kerajaan Pelalawan. Pekanbaru 
Harymawan. 1993. Dramaturgi. Bandung: Remaja Rosdakarya

Nursalim. 2003. Pengantar Kemampuan Berbahasa Indonesia. Pekanbaru: Unri Press

Soemanto, Bakdi. 2001. Jagat Teater. Yogyakarta: Pressindo
Tambajong, Japi. 1981. Dasardasar Dramaturgi. Bandung: Pustaka Prima

Yudiarni. 2002. Panggung Teater Dunia. Jogjakarta: Pustaka Gondho Suli

\section{DAFTAR INFORMAN}

$\begin{array}{ll}\text { Nama } & : \text { M. Rhiky Pranata } \\ \text { Umur } & : 25 \\ \text { Pekerjaa } & : \text { Guru } \\ \text { Alamat } & : \text { Jln. Limbungan } \\ & \text { Rumbai, Pekanbaru }\end{array}$

